Published in final edited form as:

J AIDS Clin Res. 2016 December ; 7(12): . doi:10.4172/2155-6113.1000645.

\title{
Hearing Loss and Quality of Life (QOL) among Human Immunodeficiency Virus (HIV)-Infected and Uninfected Adults
}

\author{
N Duong ${ }^{1}, \mathbf{P}$ Torre $\mathrm{III}^{2}$, G Springer ${ }^{3}, \mathbf{C}$ Cox $^{3}$, and MW Plankey ${ }^{4}{ }^{*}$ \\ ${ }^{1}$ School of Medicine and Health Sciences, George Washington University, Washington, District of \\ Columbia, USA \\ ${ }^{2}$ School of Speech, Language, and Hearing Sciences, San Diego State University, San Diego, \\ California, USA \\ ${ }^{3}$ Department of Epidemiology, Johns Hopkins University Bloomberg School of Public Health, \\ Baltimore, Maryland, USA \\ ${ }^{4}$ Department of Medicine, Division of Infectious Diseases, Georgetown University Medical Center, \\ Washington, District of Columbia, USA
}

\begin{abstract}
Objective-Research has established that human immunodeficiency virus (HIV) causes hearing loss. Studies have yet to evaluate the impact on quality of life (QOL). This project evaluates the effect of hearing loss on QOL by HIV status.

Methods-The study participants were from the Multicenter AIDS Cohort Study (MACS) and the Women's Interagency HIV study (WIHS). A total of 248 men and 127 women participated. Pure-tone air conduction thresholds were collected for each ear at frequencies from 250 through $8000 \mathrm{~Hz}$. Pure-tone averages (PTAs) for each ear were calculated as the mean of air conduction thresholds in low frequencies (i.e., 250, 500, 1000 and $2000 \mathrm{~Hz}$ ) and high frequencies (i.e., 3000, 4000, 6000 and $8000 \mathrm{~Hz}$ ). QOL data were gathered with the Short Form 36 Health Survey and Medical Outcome Study (MOS)-HIV instrument in the MACS and WIHS, respectively. A median regression analysis was performed to test the association of PTAs with QOL by HIV status.
\end{abstract}

Results-There was no significant association between hearing loss and QOL scores at low and high pure tone averages in HIV positive and negative individuals. HIV status, HIV biomarkers and treatment did not change the lack of association of low and high pure tone averages with poorer QOL.

Conclusion-Although we did not find a statistically significant association of hearing loss with QOL by HIV status, testing for hearing loss with aging and recommending treatment may offset any presumed later life decline in QOL.

This is an open-access article distributed under the terms of the Creative Commons Attribution License, which permits unrestricted use, distribution, and reproduction in any medium, provided the original author and source are credited.

*Corresponding author: Michael W Plankey, Department of Medicine, Division of Infectious Diseases, Georgetown University Medical Center, 2115 Wisconsin Ave, NW, Suite 130, Washington DC, 20007, USA; Tel: 202-784-2607; Fax: 202-784-0791; mwp23@georgetown.edu. 


\section{Keywords}

Multicenter AIDS cohort study; Women's interagency HIV study; Auditory impairment; QOL

\section{Introduction}

Presbycusis, bilateral insidious hearing loss and cochlear dysfunction, is a degenerative process characterized by three key elements: deterioration of auditory sensitivity, loss of sensory cells, and loss of central auditory processing functions [1,2]. It is one of the most prevalent chronic conditions, and is the most common sensory modality loss in the elderly population. It is estimated that over $25-40 \%$ of those over 65 year experience some form of hearing impairment [2-4]. Hearing loss has been found to decrease quality of life (QOL) measures via different mechanisms. Basically it compromises communication and thus one's social function [2,5-13]. Individuals with hearing loss are more susceptible to experiencing mental and physical health decline. Currently, there is a lack of resources and awareness for hearing loss, which poses a large public health burden [9].

Otologic symptoms and conditions have been reported in patients with human immunodeficiency virus infection and acquired immune deficiency syndrome (HIV/AIDS) [14-22]. Shouten et al. investigated the association of antiretroviral therapy using zidovudine (AZT) or didanosine (ddI) with hearing sensitivity [23]. There were no statistically significant changes in either high or low pure tone average frequencies, after accounting for age, noise exposure, CD4+ cell count, and HIV RNA viral load. van der Westhuizen et al. found that age, gender and race matched HIV-infected adults had an approximately $34 \%$ higher rate of hearing loss (HL) using pure tone averages of $0.5,1$ and $2 \mathrm{kHz}>25$ decibels (dB) compared to controls (approximately 4\%) [24]. HIV-infected adults also had higher pure-tone thresholds across all of the frequencies measured $(0.5,1,2,3$ and $4 \mathrm{kHz})$ and significantly higher rate of sensorineural hearing loss in those adults with CDC Class C disease progression status. Luque et al. found no significant difference in hearing loss (defined as four-frequency $(0.5,1,2$ and $4 \mathrm{kHz})$ pure tone averages $>25 \mathrm{~dB} \mathrm{HL}$ in either ear) among HIV-infected compared to uninfected adults [25]. This loss among the HIV-infected adults was independent of HIV duration, HIV RNA viral load, and baseline and nadir CD4+ cell count. However, the prevalence of hearing loss was $18.9 \%$ with late stage HIV disease. Maro et al. study of $449 \mathrm{HIV}$-infected and 202 HIV-uninfected adults [26] found no significant differences in hearing sensitivity thresholds for either ear adjusted for age, sex, and noise exposure and whether they were taking antiretroviral medications or not. Lastly, Torre and our group [27] analyzed hearing data from the Multicenter AIDS Cohort Study (MACS) [28] and Women's Interagency HIV study (WIHS) [29]. We found 12\% poorer low (250 to $2000 \mathrm{~Hz}$ ) and $18 \%$ poorer high $(3000$ to $8000 \mathrm{~Hz}$ ) frequency hearing among 117 HIV-infected men and 105 women as compared to 174 HIV-uninfected adults. HIV disease biomarkers and anti-retroviral treatment history did not explain these differences. In addition to studies investigating the relationship of peripheral hearing loss and HIV infection, studies have shown that HIV affects the central audiotory system [30-34], which are consistent with other HIV-related central nervous system disorders [35,36]. 
QOL measures reflect disease burden, monitor changes in health, and track treatment efficacy. It is a multi-dimensional concept that includes psychosocial, psychological, physical and mental well-being $[5,6,8,37,38]$. A study by Wong et al. found that the Chinese perceive hearing loss as a natural part of aging and that they isolate themselves irrespective of the presence or absence hearing loss [38]. Nonetheless, the hearing impaired demonstrated an overall worse general and hearing specific QOL. One study found that bilateral, combined high and low frequency loss had the most significant impact on QOL [5]. In another study people with idiopathic sudden sensorineural hearing loss (ISHL) and bilateral sensorineural hearing loss had worse QOL measures than that of average Japanese patients except for bodily pain and vitality scores [39].

Hearing loss has been shown to be independently associated with social isolation [40-42], which can adversely impact QOL among older adults [43]. Social isolation can be driven by stigma associated with marginalizing chronic medical conditions such as HIV [44]. In a study of a Veterans Affairs population with and without HIV, Greysen et al. [21] found that social isolation was a risk factor for increased rates of hospitalization and mortality irrespective of HIV status. However, they also demonstrated that being HIV+ as well as increasing age was associated with higher self-reported isolation scores. [45]. Therefore we conceptualized the association between objective clinical outcomes (such as hearing loss in this study) and subjective patient experiences (such as QOL) grounded in the overarching relationships of hearing loss and HIV, social isolation and HIV disease and social isolation and hearing loss in this work $[46,47]$.

We are not aware of any published literature that has investigated the relationship between hearing loss and QOL and whether if differs by HIV status using used data collected from the MACS and WIHS. The primary hypothesis for this study was that being hearing impaired negatively impacts QOL, and this effect is moderated by HIV status.

\section{Materials and Methods}

The institutional review boards from San Diego State University, Johns Hopkins Bloomberg School of Public Health, Georgetown University, and Whitman-Walker Health approved this study. Written informed consent was obtained from all study participants.

\section{Participants and procedures}

Participants from the Baltimore-Washington, DC site of the MACS and the Washington, DC site of the WIHS, ongoing prospective observational cohorts investigating the progression of HIV infection, comprised the study sample. The MACS consists of over $7000 \mathrm{HIV}+$ and HIV- men who have sex with men, beginning in 1984 to 1985 at 4 centers located in Baltimore, MD/Washington, D.C., Chicago, IL, Los Angeles, CA and Pittsburgh, PA. Similarly, the WIHS consists of a cohort of 3,766 women (2,791 HIV-infected and 975 HIVuninfected) were enrolled in either 1994-1995 $(n=2,623)$ or 2001-2002 $(n=1,143)$ from six United States cities [New York, NY, Chicago, IL, Los Angeles, CA, San Francisco, CA and Washington, D.C.]. Every six months, both MACS and WIHS participants complete a comprehensive physical examination, provide blood specimens for CD4+, CD8+ T-cell count and HIV-RNA determination and complete an interviewer-administered questionnaire, 
which provided data regarding socio-demographics and medical history including antiretroviral therapy use. The MACS and WIHS uses a standard definition of HAART adapted from the Department of Health and Human Services/Kaiser Panel guidelines [48]. Specific details regarding the MACS and WIHS study design and recruitment are outlined elsewhere [29].

The participants completed a clinical hearing examination consisting of an otoscopic examination, tympanometry, and pure-tone air and bone conduction testing. Full details of the testing protocol are outlined elsewhere [27].

\section{Primary predictor variables}

Pure-tone bone and air conduction testing results were used to assess the participants' hearing loss. Pure-tone air conduction thresholds were measured in each ear at 250, 500, 1000, 2000, 3000, 4000, 6000 and $8000 \mathrm{~Hz}$. Pure-tone averages (PTAs) for each ear were calculated as the mean of air conduction thresholds in low frequencies (LPTA: i.e., 250, 500, 1000 and $2000 \mathrm{~Hz}$ ) and high frequencies (HPTA: i.e., 3000, 4000, 6000 and $8000 \mathrm{~Hz}$ ), respectively. Participant's lowest HPTA and LPTA were used as the primary predictor variables.

\section{Covariates}

Participant's age, race/ethnicity (black vs. non-black), and HIV status were investigated as covariates. For the sub-analyses among the HIV+ participants only, CD4+ T-cell count, CD8+ T-cell count, ever being diagnosed with clinical AIDS, $\log _{10}$ HIV RNA and cumulative duration (years) of antiretroviral therapy (ART) use classified as non-nucleotide/ nucleoside reverse transcriptase inhibitor (NNRTI), nucleotide/nucleoside reverse transcriptase inhibitor (NRTI) and protease inhibitor (PI).

Any AIDS-defining illnesses including a history of pulmonary tuberculosis were selfreported according to the 1993 CDC definition of AIDS. Cumulative duration (years) of use of each class of ART was calculated on the basis of the number of ART medications reported in each classification and weighted for self-reported adherence. Weights were calculated by multiplying the number of ART medications at each visit by the adherence level, and the weighted values then cumulated. The weights were $1,0.975,0.85,0.375$ and 0 for adherence levels of $100 \%, 95 \%$ to $99 \%, 75 \%$ to $94 \%$, less than $75 \%$ and $0 \%$, respectively. ART use prior to October 1998 was considered $100 \%$ adherent.

In the MACS, plasma HIV RNA concentrations were measured using the COBAS Ultrasensitive Amplicor HIV-1 monitor assay (Roche Molecular Systems), sensitive to 50 copies HIV RNA/mL; or the Taqman HIV-1 Test (Roche Molecular Systems), sensitive to 20 copies HIV RNA/mL. In the WIHS, plasma HIV RNA was measured using the COBAS AmpliPrep/COBAS TaqMan HIV-1 Test (Roche Molecular Systems), sensitive to 20 or 48 copies HIV RNA/mL. Values were $\log 10$ transformed for statistical analysis. CD4+ and CD8+ T-cell counts were measured for HIV+ men and women at each study visit using standardized flow cytometry and a complete blood cell count. Laboratory results (CD4+, CD8+, HIV RNA) collected within 1 year prior to the hearing testing date hearing testing date were used for this analysis. 


\section{Outcome variable}

Participants' QOL score during the 18 months following the hearing testing was the outcome variable of interest. Higher scores indicate better QOL and function. In the MACS, QOL data were collected using the Short Form-36 Health Survey (SF-36) annually beginning in April 1994, which consists of 8 domains. The physical component score and the mental component scores were calculated following Ware's method [49] and normalized to a mean of $50+/-10$ [50]. Both physical and mental QOL scores were investigated for the male participants. For the women in the WIHS, annual QOL data were collected using a shortened version of the Medical Outcome Study (MOS)-HIV instrument developed by Bozzette et al. beginning in October 1998 [51]. The shortened version has 21 items representing 9 domains that include: physical functioning, role functioning, energy/fatigue, social functioning, cognitive functioning, pain, emotional well-being, perceived health index and current health perception. The score for each domain is calculated by averaging the raw scores for each corresponding item based on a 0-100 scale with higher scores representing better physical, mental and social functioning. A summary score is calculated using the scores from 6 domains (physical functioning, role functioning, energy/fatigue, social functioning, pain and emotional well-being) based on an established algorithm [52]. The summary QOL index was used for the female participants.

\section{Statistical analysis}

The QOL data were analyzed for each cohort separately due to the different QOL measuring methods. Because of the skewed distribution of the residuals in the PTA data when analyzing QOL measurements, a median regression analysis was performed on the untransformed data with bootstrap standard errors and confidence intervals. A total of 2000 bootstrap samples were selected for each model, and confidence intervals were based on the percentile method. In the model with both HIV+ and HIV- participants, the covariates included age, race/ethnicity, HIV status, lowest LPTA and HPTA. Separate models were constructed to examine QOL data for HIV+ participants only. For models restricted to the HIV+ participants, the covariates were CD4+ T-cell counts, CD8+ T-cells, ever AIDS, $\log _{10}$ HIV RNA and cumulative years of ART use, besides age and race/ethnicity. Regression models were performed using the SAS procedure QUANTREG, Version 9.3.

\section{Results}

Among the 375 participants (213 HIV+, 57\%) who had a QOL measurement within 18 months after pure-tone audiometry testing, there were 248 men with the average age of 56.9 years old $(\mathrm{SD}=8.8)$, of whom $112(45 \%)$ were $\mathrm{HIV}+$ and 127 women with a mean age of $47.9(\mathrm{SD}=8.4)$, of whom $101(80 \%)$ were HIV+. The characteristics of the study participants are summarized by HIV status and gender in Table 1. Compared to the HIV-participants, the HIV+ participants with higher proportions of female and black race/ethnicity were younger and had similar values of the lowest PTAs in low frequencies but lower values in high frequencies. Among the HIV+ participants, men had a longer cumulative duration of NRTI and NNRTI therapy but a shorter duration of PI therapy compared with women; the HIV+ men had higher CD4+ and CD8+ cell counts; and the HIV+ women had a higher proportion of clinical AIDS. 
The results of the multivariable analyses are shown in Tables 2-4. Consistent with our primary hypothesis of effect modification, our initial models included two-way interactions between hearing loss and HIV status. None of these interactions were significant, (data not shown) however, and we therefore present results for main effect models without interaction terms. For men, there was no statistically significant association of HPTA and LPTA after adjusting for age, race/ethnicity and HIV status. For women, there was a borderline negatively statistically significant association with LPTA $(p=0.07)$ only and QOL index. For both men and women, the relationship of hearing loss and QOL did not differ by HIV status.

Tables 5-7 show the results of the multivariable analyses restricted to the HIV+ participants only. There were no statistically significant associations of age, race/ethnicity and HIV status including ART use, virologic and immunologic markers with both HPTA and LPTA loss and men's physical/mental QOL score and women's summary QOL index, except that ever AIDS was negatively associated with higher women's QOL index ( $p=0.03)$.

\section{Conclusion}

Hearing loss affects multiple forms of social, emotional and physical function [9]. The literature reports its association with mood disorders, increased risks of falls and hospitalizations, early mortality and even a rapid deterioration in cognitive function [9]. One study found that HIV+ individuals have poorer hearing across all frequencies as compared to HIV- individuals [27]. This present study is an extension of that knowledge. In this study, we sought to determine if hearing loss in HIV+ and HIV- people impacts QOL differentially at low and high frequencies. In this study, we did not find these relationships in HIV+ individuals.

There are a limited number of studies in the literature that look at hearing loss and its impact on QOL, and none to our knowledge, that have attempted to examine the effect that HIV status has on this relationship. The few studies that do exist have used self-reported hearing loss in evaluating its impact on QOL [41,53-55] and they have found that higher frequency loss was associated with a feeling of social limitation and poorer emotional well-being. Most have had small sample sizes or were cross-sectional in nature, thus causality could not be inferred and the results could have been a result of other comorbidities. However, an advantage of self-report is that subtle forms of impairment could potentially be identified and it is also more representative of function in everyday life. There are a few studies that used clinical assessment of hearing loss to study its impact on QOL measures. Some studies used PTA to define hearing loss [56-58] while others used a free field voice test [59,60]. All found a negative impact of loss on social and emotional function, but Thomas et al. reported that hearing deficits were not associated with emotional status or social integration. One study established that measured hearing loss was associated with higher risk of mortality in men and this effect was moderated by mood levels [59]. To our knowledge, there has been only one population-based study to date that used clinical audiometric data. Dalton et al. [8] found that communication difficulties, as assessed by a hearing handicap survey, communication questionnaire, and audiometry testing were significantly associated with impaired functions of daily living as measured by the SF-36 in older adults. The participants in the Dalton study were much older (average age 69 years) than those in the MACS and 
WIHS, so that age related hearing loss (both measured and self-reported) is likely to be more prevalent and therefore to impact QOL.

The limitations of this present study include a relatively small sample size and limited variability of QOL measurements. Additionally QOL was not measured longitudinally. Although this may not be the first study that uses clinical assessment of hearing loss, this is the first study to examine the impact of hearing loss on QOL in HIV disease. Given our previous published findings [27] demonstrating higher risk of hearing loss among this sample of HIV+ men and women, our ability to detect poorer QOL may be temporally premature given the sample is middle-aged. Health care providers should still be more cognizant in general of the need to test for hearing loss with aging and recommend treatment in order to identify hearing loss as early as possible to offset the possible decline in QOL later in life.

\section{Acknowledgments}

The authors thank Ying Li, PhD, from Georgetown University Medical Center, for technical management of this manuscript.

Funding: This work was supported by the National Institute on Deafness and Other Communication Disorders (NIDCD) and National Institutes of Health (NIH), via interagency agreement with the National Institute of Allergy and Infectious Diseases (NIAID), NIH for Cooperative Agreements [U01 AI-035042 (MACS), U01 AI-034994 (WIHS)]. Support of the MACS Baltimore-Washington, DC site was provided by the NIAID, with additional supplemental funding from the National Cancer Institute [U01-AI-35042] and General Clinic Research Center [UL1-RR025005]. Support of the WIHS Metropolitan Washington, DC site was provided by the NIAID [U01AI-34994] and by the Eunice Kennedy Shriver National Institute of Child Health and Human Development (NICHD), NIH [U01-HD-32632]. The MACS website is located at http://aidscohortstudy.org/ and the WIHS website is https://statepi.jhsph.edu/wihs/wordpress/

\section{References}

1. Frisina RD. Age-related hearing loss: Ear and brain mechanisms. Ann N Y Acad Sci. 2009; 1170:708-717. [PubMed: 19686217]

2. Li-Korotky HS. Age-related hearing loss: Quality of care for quality of life. Gerontologist. 2012; 52:265-271. [PubMed: 22383543]

3. Cruickshanks KJ, Wiley TL, Tweed TS, Klein BE, Klein R, et al. Prevalence of hearing loss in older adults in Beaver Dam, Wisconsin. The Epidemiology of Hearing Loss Study. Am J Epidemiol. 1998; 148:879-886. [PubMed: 9801018]

4. Gopinath B, Wang JJ, Schneider J, Burlutsky G, Snowdon J, et al. Depressive symptoms in older adults with hearing impairments: The blue mountains study. J Am Geriatr Soc. 2009; 57:13061308. [PubMed: 19570163]

5. Chia EM, Wang JJ, Rochtchina E, Cumming RR, Newall P, et al. Hearing impairment and healthrelated quality of life: The blue mountains hearing study. Ear Hear. 2007; 28:187-195. [PubMed: 17496670]

6. Ciorba A, Benatti A, Bianchini C, Aimoni C, Volpato S, et al. High frequency hearing loss in the elderly: Effect of age and noise exposure in an Italian group. J Laryngol Otol. 2011; 125:776-780. [PubMed: 21729437]

7. Ciorba A, Bianchini C, Pelucchi S, Pastore A. The impact of hearing loss on the quality of life of elderly adults. Clin Interv Aging. 2012; 7:159-163. [PubMed: 22791988]

8. Dalton DS, Cruickshanks KJ, Klein BE, Klein R, Wiley TL, et al. The impact of hearing loss on quality of life in older adults. Gerontologist. 2003; 43:661-668. [PubMed: 14570962]

9. Davis A, McMahon CM, Pichora-Fuller KM, Russ S, Lin F, et al. Aging and hearing health: The life-course approach. Gerontologist. 2016; 56(2):S256-267. [PubMed: 26994265] 
10. Heine C, Browning CJ. Communication and psychosocial consequences of sensory loss in older adults: overview and rehabilitation directions. Disabil Rehabil. 2002; 24:763-773. [PubMed: 12437862]

11. Mondelli MF, Souza PJ. Quality of life in elderly adults before and after hearing aid fitting. Braz J Otorhinolaryngol. 2012; 78:49-56. [PubMed: 22714847]

12. Nachtegaal J, Smit JH, Smits C, Bezemer PD, van Beek JH, et al. The association between hearing status and psychosocial health before the age of 70 years: Results from an internet-based national survey on hearing. Ear Hear. 2009; 30:302-312. [PubMed: 19322094]

13. Shiovitz-Ezra S, Ayalon L. Situational versus chronic loneliness as risk factors for all-cause mortality. Int Psychogeriatr. 2010; 22:455-462. [PubMed: 20003631]

14. Rarey KE. Otologic pathophysiology in patients with human immunodeficiency virus. Am J Otolaryngol. 1990; 11:366-369. [PubMed: 2281839]

15. Chandrasekhar SS, Siverls V, Sekhar HK. Histopathologic and ultrastructural changes in the temporal bones of HIV-infected human adults. Am J Otol. 1992; 13:207-214. [PubMed: 1609848]

16. Chandrasekhar SS, Connelly PE, Brahmbhatt SS, Shah CS, Kloser PC, et al. Otologic and audiologic evaluation of human immunodeficiency virus-infected patients. Am J Otolaryngol. 2000; 21:1-9. [PubMed: 10668670]

17. Zuniga J. Communication disorders and HIV disease. J Int Assoc Physicians AIDS Care. 1999; 5:16-23. [PubMed: 11367045]

18. Khoza K, Ross E. Auditory function in a group of adults infected with HIV/AIDS in Gauteng, South Africa. S Afr J Commun Disord. 2002; 49:17-27. [PubMed: 14968699]

19. Rinaldo A, Brandwein MS, Devaney KO, Ferlito A. AIDS-related otological lesions. Acta Otolaryngol. 2003; 123:672-674. [PubMed: 12953763]

20. Hausler R, Vibert D, Koralnik IJ, Hirschel B. Neuro-otological manifestations in different stages of HIV infection. Acta Otolaryngol. 1991; (481):515-521. [PubMed: 1887778]

21. Kallail KJ, Downs D, Scherz J, Sweet D, Zackula RE. Prevalence of communication disorders in HIV-infected adults. J Int Assoc Provid AIDS Care. 2014; 13:8-11. [PubMed: 24284265]

22. Heinze B, Swanepoel DW, Hofmeyr LM. Systematic review of vestibular disorders related to human immunodeficiency virus and acquired immunodeficiency syndrome. J Laryngol Otol. 2011; 125:881-890. [PubMed: 21729430]

23. Schouten JT, Lockhart DW, Rees TS, Collier AC, Marra CM. A prospective study of hearing changes after beginning zidovudine or didanosine in HIV-1 treatment-naïve people. BMC Infect Dis. 2006; 6:28. [PubMed: 16504011]

24. van der Westhuizen Y, Swanepoel de W, Heinze B, Hofmeyr LM. Auditory and otological manifestations in adults with HIV/AIDS. Int J Audiol. 2013; 52:37-43. [PubMed: 23043519]

25. Luque AE, Orlando MS, Leong UC, Allen PD, Guido JJ, et al. Hearing function in patients living with HIV/AIDS. Ear Hear. 2014; 35:e282-e290. [PubMed: 25127320]

26. Maro II, Moshi N, Clavier OH, MacKenzie TA, Kline-Schoder RJ, et al. Auditory impairments in HIV-infected individuals in Tanzania. Ear Hear. 2014; 35:306-317. [PubMed: 24441742]

27. Torre P 3rd, Hoffman HJ, Springer G, Cox C, Young MA, et al. Hearing loss among HIVseropositive and HIV-seronegative men and women. JAMA Otolaryngol Head Neck Surg. 2015; 141:202-210. [PubMed: 25541676]

28. Kaslow RA, Ostrow DG, Detels R, Phair JP, Polk BF, et al. The multicenter AIDS Cohort study: Rationale, organization and selected characteristics of the participants. Am J Epidemiol. 1987; 126:310-318. [PubMed: 3300281]

29. Barkan SE, Melnick SL, Preston-Martin S, Weber K, Kalish LA, et al. The women's interagency HIV study. WIHS Collaborative Study Group. Epidemiology. 1998; 9:117-125. [PubMed: 9504278]

30. Matas CG, Silva SM, Marcon Bde A, Gonçalves IC. Electrophysiological manifestations in adults with HIV/AIDS submitted and not submitted to antiretroviral therapy. Pro Fono. 2010; 22:107113. [PubMed: 20640373]

31. Matas CG, Leite RA, Magliaro FC, Goncalves IC. Audiological and electrophysiological evaluation of children with acquired immunodeficiency syndrome (AIDS). Braz J Infect Dis. 2006; 10:264-268. [PubMed: 17293909] 
32. Welkoborsky HJ, Lowitzsch K. Auditory brain stem responses in patients with human immunotropic virus infection of different stages. Ear Hear. 1992; 13:55-57. [PubMed: 1541374]

33. Bankaitis AE, Keith RW. Audiological changes associated with HIV infection. Ear Nose Throat J. 1995; 74:353-359. [PubMed: 7796743]

34. Lalwani AK, Sooy CD. Otologic and neurologic manifestations of acquired immunodeficiency syndrome. Otolaryngol Clin N Am. 1992; 25:1183-1198.

35. Spudich S, González-Scarano F. HIV-1-related central nervous system disease: Current issues in pathogenesis, diagnosis and treatment. Cold Spring Harb Perspect Med. 2012; 2:a007120. [PubMed: 22675662]

36. Price RW, Spudich S. Antiretroviral therapy and central nervous system HIV type 1 infection. J Infect Dis. 2008; 197(3):S294-S306. [PubMed: 18447615]

37. Chew HS, Yeak S. Quality of life in patients with untreated age-related hearing loss. J Laryngol Otol. 2010; 124:835-841. [PubMed: 20403224]

38. Wong LL, Cheng LK. Quality of life in older Chinese-speaking adults with hearing impairment. Disabil Rehabil. 2012; 34:655-664. [PubMed: 22080747]

39. Sano H, Okamoto M, Ohhashi K, Iwasaki S, Ogawa K. Quality of life reported by patients with idiopathic sudden sensorineural hearing loss. Otol Neurotol. 2013; 34:36-40. [PubMed: 23232830]

40. Gates GA, Mills JH. Presbycusis. Lancet. 2005; 366:1111-1120. [PubMed: 16182900]

41. Strawbridge WJ, Wallhagen MI, Shema SJ, Kaplan GA. Negative consequences of hearing impairment in old age: A longitudinal analysis. Gerontologist. 2000; 40:320-326. [PubMed: 10853526]

42. Ramage-Morin PL. Hearing difficulties and feelings of social isolation among Canadians aged 45 or older. Health Rep. 2016; 27:3-12.

43. Hawton A, Green C, Dickens AP, Richards SH, Taylor RS, et al. The impact of social isolation on the health status and health-related quality of life of older people. Qual Life Res. 2011; 20:57-67. [PubMed: 20658322]

44. Biordi, DL., Nicholson, NR. Chronic illness: Impact and interventions. Boston: Jones and Bartlett Publishers; LLC: 1995. p. 168-190.

45. Greysen SR, Horwitz LI, Covinsky KE, Gordon K, Ohl ME, et al. Does social isolation predict hospitalization and mortality among HIV+ and uninfected older veterans? J Am Geriatr Soc. 2013; 61:1456-1463. [PubMed: 23927911]

46. Sousa KH, Kwok OM. Putting Wilson and Cleary to the test: Analysis of a HRQOL conceptual model using structural equation modeling. Qual Life Res. 2006; 15:725-737. [PubMed: 16688505]

47. Nokes KM, Holzemer WL, Corless IB, Bakken S, Brown MA, et al. Health-related Quality of life in persons younger and older than 50 who are living with HIV/AIDS. Research on Aging. 2000; 22:290-310.

48. Guidelines for the Use of Antiretroviral Agents in HIV-1-Infected Adults and Adolescents. Department of Health and Human Service and the Henry J Kaiser Family Foundation Panel on Clinical Practices for the Treatment of HIV Infection; 2004.

49. Ware, JE., Jr, Kosinski, M. SF-36 Physical and Mental Health Summary Scales: A Manual for Users of Version 1. Quality Metric Inc; Lincoln, RI: 2001.

50. Erlandson KM, Reynolds SM, Cox C, Palella FJ, Witt MD, et al. Self-reported body fat change in HIV-infected men is a marker of decline in physical health-related quality of life with aging, independent of co-morbidity. PLoS ONE. 2014; 9:e114166. [PubMed: 25436612]

51. Bozzette SA, Hays RD, Berry SH, Kanouse DE, Wu AW. Derivation and properties of a brief health status assessment instrument for use in HIV disease. J Acquir Immune Defic Syndr Hum Retrovirol. 1995; 8:253-265. [PubMed: 7859137]

52. Revicki DA, Sorensen S, Wu AW. Reliability and validity of physical and mental health summary scores from the Medical Outcomes Study HIV Health Survey. Med Care. 1998; 36:126-137. [PubMed: 9475468]

53. Bazargan M, Baker RS, Bazargan SH. Sensory impairments and subjective well-being among aged African American persons. J Gerontol B Psychol Sci Soc Sci. 2001; 56:P268-278. [PubMed: $11522801]$ 
54. Magilvy JK. Quality of life of hearing-impaired older women. Nurs Res. 1985; 34:140-144. [PubMed: 3846919]

55. Scherer MJ, Frisina DR. Characteristics associated with marginal hearing loss and subjective wellbeing among a sample of older adults. J Rehabil Res Dev. 1998; 35:420-426. [PubMed: 10220220]

56. Bess FH, Lichtenstein MJ, Logan SA, Burger MC, Nelson E. Hearing impairment as a determinant of function in the elderly. J Am Geriatr Soc. 1989; 37:123-128. [PubMed: 2910970]

57. Mulrow CD, Aguilar C, Endicott JE, Tuley MR, Velez R, et al. Quality-of-life changes and hearing impairment. A randomized trial. Ann Intern Med. 1990; 113:188-194. [PubMed: 2197909]

58. Thomas PD, Hunt WC, Garry PJ, Hood RB, Goodwin JM, et al. Hearing acuity in a healthy elderly population: effects on emotional, cognitive and social status. J Gerontol. 1983; 38:321-325. [PubMed: 6841927]

59. Appollonio I, Carabellese C, Frattola L, Trabucchi M. Effects of sensory aids on the quality of life and mortality of elderly people: A multivariate analysis. Age Ageing. 1996; 25:89-96. [PubMed: 8670534]

60. Carabellese C, Appollonio I, Rozzini R, Bianchetti A, Frisoni GB, et al. Sensory impairment and quality of life in a community elderly population. J Am Geriatr Soc. 1993; 41:401-407. [PubMed: 8463527] 


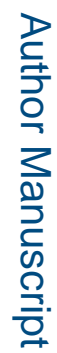

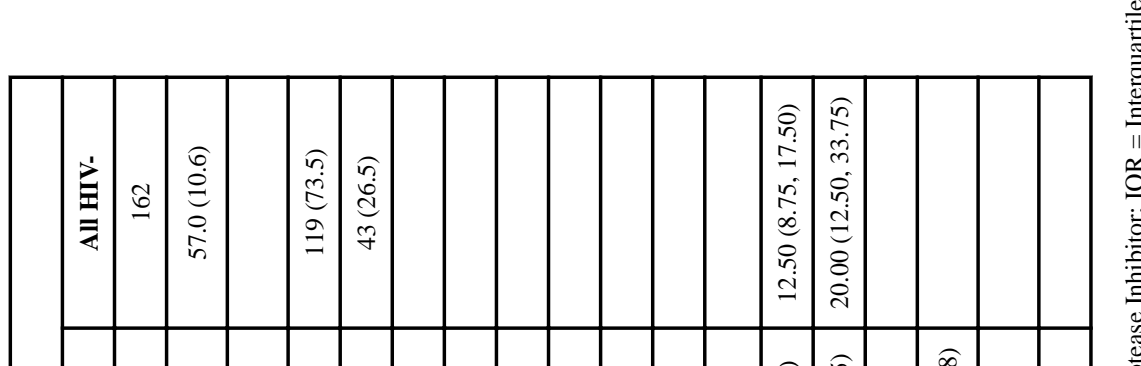

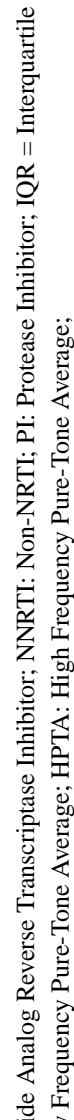

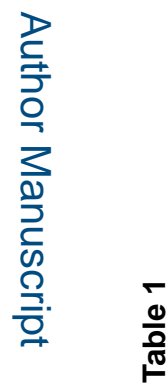

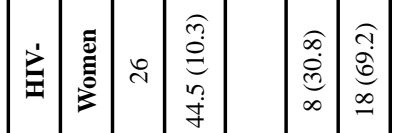

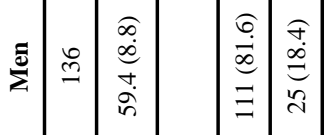

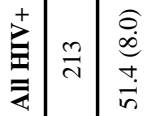

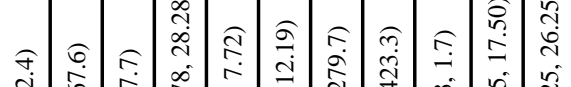

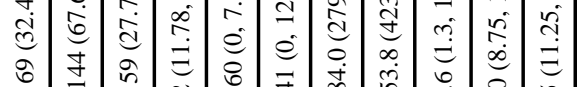

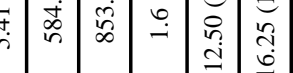

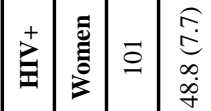

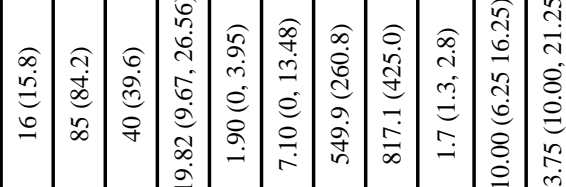

I

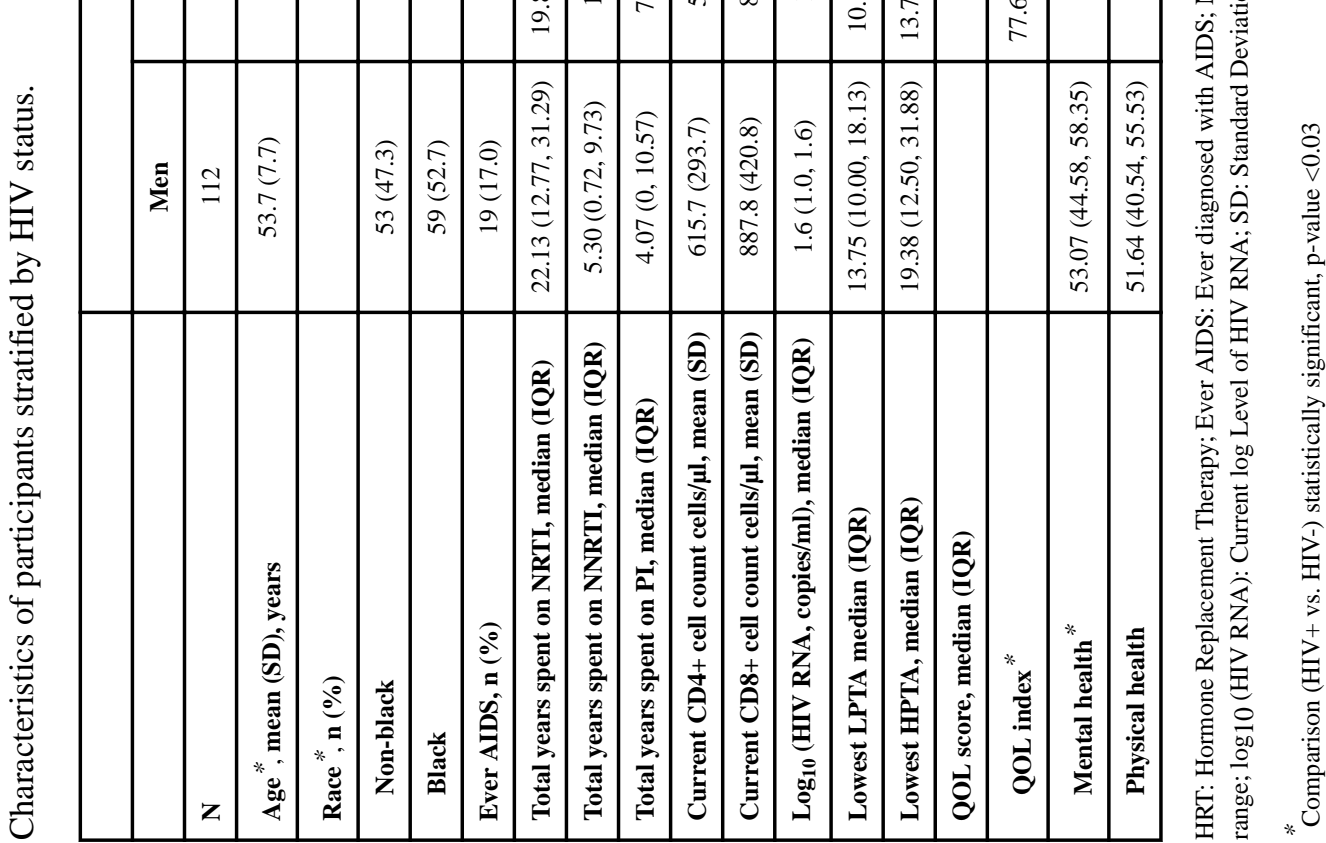

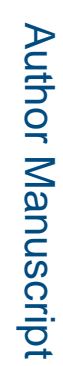

J AIDS Clin Res. Author manuscript; available in PMC 2017 February 16. 


\section{Table 2}

Estimates of each effect for women's QOL index.

\begin{tabular}{|l|c|c|c|}
\hline Effect & Estimate & Confidence Intervals & $\boldsymbol{p}$ \\
\hline Age, 10-yr increase & -2.53 & $(-7.67,2.25)$ & 0.29 \\
\hline Black & 5.91 & $(-9.35,15.26)$ & 0.67 \\
\hline HIV+ & -3.43 & $(-12.24,6.50)$ & 0.48 \\
\hline Lowest HPTA & -0.16 & $(-0.73,0.67)$ & 0.98 \\
\hline Lowest LPTA & -0.70 & $(-1.83,0.05)$ & 0.07 \\
\hline
\end{tabular}

LPTA: Low Frequency Pure-Tone Average; HPTA: High Frequency Pure-Tone Average; QOL: Quality Of Life 


\section{Table 3}

Estimates of each effect for men's physical health QOL score.

\begin{tabular}{|l|c|c|c|}
\hline Effect & Estimate & Confidence Intervals & $\boldsymbol{p}$ \\
\hline Age, 10 year increase & -1.21 & $(-3.22,0.48)$ & 0.18 \\
\hline Black & -2.97 & $(-7.07,0.65)$ & 0.12 \\
\hline HIV+ & -1.34 & $(-5.22,0.66)$ & 0.23 \\
\hline Lowest HPTA & -0.02 & $(-0.14,0.09)$ & 0.64 \\
\hline Lowest LPTA & -0.11 & $(-0.39,0.20)$ & 0.61 \\
\hline
\end{tabular}

LPTA: Low Frequency Pure-Tone Average; HPTA: High Frequency Pure-Tone Average; QOL: Quality Of Life 
Table 4

Estimates of each effect for men's mental health QOL score.

\begin{tabular}{|l|c|c|c|}
\hline Effect & Estimate & Confidence Intervals & $\boldsymbol{p}$ \\
\hline Age, 10 year increase & 3.63 & $(1.61,4.99)$ & $<0.001$ \\
\hline Black & 1.06 & $(-2.35,3.26)$ & 0.51 \\
\hline HIV+ & -2.06 & $(-4.23,0.79)$ & 0.16 \\
\hline Lowest HPTA & -0.02 & $(-0.11,0.10)$ & 0.70 \\
\hline Lowest LPTA & -0.03 & $(-0.32,0.17)$ & 0.76 \\
\hline
\end{tabular}

LPTA: Low Frequency Pure-Tone Average; HPTA: High frequency pure-tone average; QOL: Quality Of Life 


\section{Table 5}

Estimates of each effect for HIV+ women's QOL index.

\begin{tabular}{|l|c|c|c|}
\hline Effect & Estimate & Confidence Intervals & $\boldsymbol{p}$ \\
\hline Age, 10 year increase & -2.73 & $(-9.39,2.60)$ & 0.24 \\
\hline Black & 7.77 & $(-4.57,18.49)$ & 0.22 \\
\hline CD4+ cell count-100 increase & 1.36 & $(-0.87,3.26)$ & 0.19 \\
\hline CD8+ cell count-100 increase & -0.04 & $(-0.88,1.19)$ & 0.80 \\
\hline Ever AIDS & -11.97 & $(-23.29,-1.35)$ & 0.03 \\
\hline Log $_{10}$ (HIV RNA, copies/ml) & -1.51 & $(-5.93,2.53)$ & 0.48 \\
\hline Total years spent on NNRTI & 0.32 & $(-1.32,1.86)$ & 0.82 \\
\hline Total years spent on NRTI & -0.40 & $(-0.90,0.41)$ & 0.37 \\
\hline Total years spent on PI & 0.43 & $(-0.44,1.21)$ & 0.37 \\
\hline Lowest HPTA & 0.04 & $(-0.72,0.70)$ & 0.83 \\
\hline Lowest LPTA & -0.24 & $(-1.64,0.70)$ & 0.59 \\
\hline
\end{tabular}

LPTA: Low Frequency Pure-Tone Average; HPTA: High frequency pure-tone average; QOL: Quality Of Life 
Table 6

Estimates of each effect for HIV+ men's physical health QOL score.

\begin{tabular}{|l|c|c|c|}
\hline Effect & Estimate & Confidence Intervals & $\boldsymbol{p}$ \\
\hline Age, 10 year increase & -0.66 & $(-5.86,3.29)$ & 0.58 \\
\hline Black & -1.04 & $(-8.14,4.86)$ & 0.53 \\
\hline CD4+ cell count, 100 increase & -0.34 & $(-1.42,0.96)$ & 0.60 \\
\hline CD8+ cell count, 100 increase & 0.42 & $(-0.54,0.92)$ & 0.57 \\
\hline Ever AIDS & -5.69 & $(-12.43,4.69)$ & 0.45 \\
\hline Log 1 (HIV RNA, copies/ml) & -2.29 & $(-5.73,1.61)$ & 0.14 \\
\hline Total years spent on NNRTI & 0.33 & $(-0.62,0.94)$ & 0.48 \\
\hline Total years spent on NRTI & 0.08 & $(-0.16,0.48)$ & 0.35 \\
\hline Total years spent on PI & -0.10 & $(-0.69,0.22)$ & 0.30 \\
\hline Lowest HPTA & -0.09 & $(-0.31,0.25)$ & 0.74 \\
\hline Lowest LPTA & 0.18 & $(-0.58,0.63)$ & 0.68 \\
\hline
\end{tabular}

LPTA: Low Frequency Pure-Tone Average; HPTA: High Frequency Pure-Tone Average; QOL: Quality Of Life 
Table 7

Estimates of each effect for HIV+ men's mental health QOL score.

\begin{tabular}{|l|c|c|c|}
\hline Effect & Estimate & Confidence Intervals & $\boldsymbol{p}$ \\
\hline Age, 10 year increase & 3.03 & $(-0.65,6.92)$ & 0.09 \\
\hline Black & 4.03 & $(-4.85,7.34)$ & 0.47 \\
\hline CD4+ cell count, 100 increase & 0.06 & $(-1.15,0.74)$ & 0.67 \\
\hline CD8+ cell count, 100 increase & -0.19 & $(-0.73,0.54)$ & 0.70 \\
\hline Ever AIDS & -0.66 & $(-12.84,3.24)$ & 0.47 \\
\hline Log $\mathbf{1 0}$ (HIV RNA, copies/ml) & -1.55 & $(-2.99,2.42)$ & 0.42 \\
\hline Total years spent on NNRTI & 0.25 & $(-0.60,0.94)$ & 0.64 \\
\hline Total years spent on NRTI & 0.05 & $(-0.27,0.38)$ & 0.60 \\
\hline Total years spent on PI & 0.04 & $(-0.23,0.73)$ & 0.80 \\
\hline Lowest HPTA & 0.11 & $(-0.27,0.31)$ & 0.80 \\
\hline Lowest LPTA & -0.26 & $(-0.69,0.37)$ & 0.75 \\
\hline
\end{tabular}

LPTA: Low Frequency Pure-Tone Average; HPTA: High Frequency Pure-Tone Average; QOL: Quality Of Life 